\title{
Reflexões sobre adolescências e a complexidade das comunidades de afeto no processo socioeducativo
}

Teresa Cristina Othenio Cordeiro Carreteiro*

Resumo: Este artigo, cujo campo teórico é o da sociologia clínica e da psicossociologia, tem por propósito discutir brevemente as adolescências brasileiras, enfatizando aquela que é mais fragilizada e que pode ser incluída no sistema socioeducativo. Neste ponto, faz uma inflexão para discorrer sobre este sistema. Sugere que as intervenções institucionais considerem a perspectiva clínica e define a compreensão que as disciplinas que orientam o artigo atribuem a implicação e a escuta na formulação de suas ações. Explicita como a clínica social pode contribuir, através da ação dos profissionais, junto aos jovens que estão inseridos no sistema socioeducativo. Por fim, cita o interesse da instituição Justiça em contar com as comunidades de afeto, definidas em uma perspectiva complexa e aponta a importância de pensar e de agir em rede, de forma implicada e atenta à clínica, para poder restituir ao adolescente um lugar de sujeito de direito.

Palavras-chaves: Clínica social. Adolescências. Sistema socioeducativo. Sociologia clínica.

\section{Reflections on adolescences and the complexity}

of the "comunidades de afeto" in the socio-educational process

Abstract: This paper, which theoretical field is the clinical sociology and psychosociology, aims to briefly discuss the Brazilian adolescents, emphasizing the one that is more demunide and that can be included in the socio-educational system. At this point makes an inflection to talk about this system. It suggests interventions from institutions have sensitivity to the clinic and defines the understanding which the disciplines that guide the article attribute to the clinic, to implication and to listening in the formation of their actions. It explains how the social clinic can contribute, through the action of professionals, to youngsters who are inserted in the social education system. Finally, it cites the interest of the Justice institution to have communities of affection, defined in a complex perspective. It ends by pointing out the importance of thinking and acting in a network, implicitly and attentive to the clinic, in order to restore to the adolescent all rights to be a subject.

Keywords: Social clinic. Adolescentes. Social educational system. Comunidade de afeto. Clinical sociology.

A sociologia clínica e a psicossociologia consideram que, para se buscar compreender um fenômeno social, é preciso lançar mão de um olhar interdisciplinar, tecendo pontes e diálogos entre várias disciplinas. Na sociologia clínica há uma acentuação dos fenômenos sociais globais e políticos, visando desconstruir a ideia de eles serem considerados unicamente como "coisa" (Durkheim,

\footnotetext{
* Teresa Cristina Othenio Cordeiro Carreteiro é professora titular do Programa de Pós-graduação em Psicologia da Universidade Federal Fluminense (UFF), Rio de Janeiro, RJ, Brasil, pesquisadora do CNPq; membro fundadora do Centre Internacional de Psychosociologie, Paris; membro fundadora do Institut Internacional de Sociologie Clinique, Paris. Atualmente é membro do conselho de administração do Centre Internacional de Psychosociologie. Orcid: 0000-00015657-0043. <carreteiro.teresa@ gmail.com>.
} 
2007). É importante conceber que eles estruturam o campo social, mas também se deve pensar na repercussão que têm para os seres humanos, como eles os interiorizam, participam a solidificá-los ou a transformá-los. Esta disciplina concebe, então, os fenômenos sociais como criados por seres humanos tomados em toda sua complexidade, racionalidade, emoções e afetos, enfim, atravessados por correntes conscientes e inconscientes. A psicossociologia na sua origem se voltava ao estudo e às intervenções junto a grupos, organizações e instituições. Ela também se distinguia por um interesse acurado em traçar interlocuções com a psicanálise e outras disciplinas e pensar nas questões intrapsíquicas, interpsíquicas e grupais. Alguns psicossociólogos franceses consideravam que essa disciplina deixava de lado alguns níveis de análises mais macro que eram importantes para compreensão de questões sociais amplas e globais. Na década de 1980, retomaram a formulação de sociologia clínica (a este respeito, ver Yzaguirre \& Castillo Mendoza, 2013).

Na verdade a psicossociologia e a sociologia clínica têm o mesmo fundamento: a perspectiva clínica, ou seja, uma atenção constante às motivações, aos sentimentos e às condutas de todo sujeito individual ou social considerado em sua singularidade, dinamismo na forma de viver e de enfrentar os diversos processos nos quais está engajado.

As diferenças essenciais entre as duas abordagens, na perspectiva da intervenção, se voltam às modalidades de olhar a si e ao outro.

O psicossociólogo tem grande atenção ao seu próprio processo inconsciente, analisa sua transferência e contratransferência, se interessa tanto por suas reações quanto por aquelas de seus interlocutores, sendo estes sujeitos individuais, grupos ou instituições.

O sociólogo clínico, mesmo atento às dimensões citadas anteriormente, terá um olhar mais voltado às questões ideológicas. Buscará fazer uma distinção entre a sua ideologia e aquela do lugar onde realiza sua intervenção.

Ambas as disciplinas vão considerar os atores sociais com os quais trabalham como coprodutores de sentido.

Intervir é poder acompanhar os sujeitos em suas tarefas, escutá-los, para poder compreender junto com eles os problemas que Ihes trazem dificuldades, os obstáculos que os impedem de realizar suas atividades e os conflitos que encontram. O que é mobilizado é o sujeito face ao trabalho (Gaulejac, 2019: 252). 
Necessário ressaltar também que ambas as disciplinas têm uma perspectiva clínica, crítica e estão atentas à questão da complexidade. A clínica visa coletar elementos para entender os possíveis sentidos que englobam a questão estudada, desde um ponto de vista singular até o mais macro. A crítica se articula em permanência com a clínica, examina e reflete de forma implicada sobre as mudanças, positivas ou outras, que ocorrem com o fenômeno trabalhado ou com o campo de intervenção. Ambas afirmam a importância de se ater a teorizações múltiplas e portanto, pensam que todo fenômeno deve ser abordado em sua complexidade.

\section{A adolescência e a adolescência vulnerabilizada}

Ao nos referirmos à adolescência, não podemos deixar de citar a importância do Estatuto da Criança e do Adolescente (ECA) e os avanços das políticas públicas, trazendo consequências para os jovens, principalmente os de estratos sociais mais vulneráveis da sociedade. No entanto, hoje, todos que defendem esse estatuto ocupam um lugar militante, face aos ataques que ele tem sofrido, principalmente nas propostas de mudança da maioridade penal, fruto das críticas à criminalidade e à focalização excessiva do sistema de violência vinculado ao jovem (Pereira de Andrade \& Amaral Machado, 2017). Tal juízo ignora o conjunto do processo social, pois focaliza a violência pensando nos modos de criminalizá-la, sem atentar ao conjunto da sociedade, aos vários sistemas institucionais, juntamente com as condições concretas de existência juvenil fragilizada. Ignora os vínculos, muitas vezes precários, que se tecem junto à escola, à família, à saúde, à moradia, às oportunidades de empregos, entre outros.

O ECA criou uma ruptura com o modelo anterior, que aplicava uma política repressiva para pensar no jovem que se distanciasse da norma. $\mathrm{O}$ antigo modelo se sustentava em perspectivas filantrópicas, higienistas, moralizantes, disciplinadoras, reformistas, assistenciais e repressivas. Os jovens, para se enquadrarem às normas sociais, deveriam ser disciplinados, pois o espectro de se tornarem criminosos pairava sobre suas cabeças. À ideia de infância criminosa regia o imaginário jurídico e social da época, criando uma diferenciação entre "menor" e "criança", de acordo com o lugar social ocupado.

Diversamente, o ECA vai "visar o direito irrestrito à totalidade de indivíduos menores de 18 anos". Nesta perspectiva, o estatuto passou a atender os adolescentes protagonistas de delitos como sujeitos a quem também cabe a proteção integral e a condição de pessoas em momento específico de desenvolvimento. 
Não há dúvidas de que o ECA é um grande marco. No entanto, a condição do adolescente fragilizado socialmente é atravessada por um paradoxo. Se juridicamente ele é considerado como sujeito de direito - neste ponto existe uma igualdade entre todo e qualquer adolescente -, no horizonte social ele se sente desvalorizado. Para justificarmos esta afirmativa lançamos mão de algumas hipóteses sobre o lugar social do adolescente em conflito com a Lei.

Muitos adolescentes são depositários de uma carga social que pesa negativamente sobre suas subjetividades, eles são constantemente confrontados com a interface do direito e do favor.

A carga social depositada sobre os adolescentes em geral apresenta diferentes modulações, pois ela é distinta de acordo com o pertencimento social. Vale lembrar as teorizações de Robert Castel (1995) para examinar o peso dos componentes sociais. O sociólogo francês lança a hipótese de duas formas contemporâneas de indivíduos: os "por falta" e os "por excesso". Os que compõem o primeiro grupo contam com poucos suportes objetivos (econômicos, institucionais) e tem menores possibilidades de desenvolverem estratégias individuais, que lhes permitam escapar da dependência, para conduzirem suas vidas. Encontram-se, pois, mais assujeitados a pessoas, grupos e programas de auxílio social. Os "indivíduos por falta", geralmente têm seu pertencimento institucional marcado por aspectos negativos.

Em contraste com os primeiros, os "indivíduos por excesso" integram uma teia de pertencimento social positivo. Isso Ihes permite ter suficientes suportes em diferentes dimensões institucionais (educação, saúde, família, cultura, entre outras). Este conjunto de suportes vai garantir-Ihes a não dependência, favorecendo a construção de posições autônomas.

Não podemos pensar de modo maniqueísta. A crise que atravessa o campo social contemporâneo e o trabalho atual é como um fantasma que paira, em geral, sobre todas as famílias e os sujeitos sociais. Buscar encontrar um lugar na sociedade e lutar por ele se constitui em grande desafio (Gaulejac \& Taboada, 1994).

\section{Projetos sociais para os adolescentes}

Identificamos dois grandes projetos para os adolescentes:

i. projeto de realização; e

ii. projeto de fracasso. 


\section{Projeto de realização}

Nas categorias sociais mais favorecidas, este projeto se formula como meio de assimilar as ambições adolescentes ou aquelas que outros projetaram para eles. Os ideais de sucesso, de excelência, de autonomia financeira e de renovação da sociedade são depositados nos jovens.

As famílias tentam proporcionar aos filhos capacitações educacionais máximas, além da educação formal obrigatória. As famílias passam a ser verdadeiras gestoras da educação dos filhos (Gaulejac, 2005), mesmo se, para algumas, isto se revista de grandes sacrifícios financeiros e de fortes lutas para poderem proporcionar aos filhos uma educação de qualidade.

Os adolescentes que podem participar deste projeto são "indivíduos por excesso". Eles passam a ser equipados socioeducacionalmente para imaginar poder encontrar, no futuro, um lugar social valorizado e que Ihes traga autonomia.

\section{Projeto de fracasso}

A educação também é valor para as categoriais menos favorecidas, que vivem grandes restrições econômicas. No entanto, as famílias, em sua grande maioria, só podem incentivar os filhos a trilharem a educação formal obrigatória. Elas ficam receosas com as atividades ilícitas que muitas vezes ocorrem na proximidade dos lugares onde vivem. Buscam, portanto, fazer barreira a tais adversidades na transmissão do que chamamos "capital de integridade" (honestidade, responsabilidade e dignidade). Pretendem, pela exaltação de valores morais, evitar que os filhos participem ou se interessem por atividades consideradas suspeitas.

Muitos adolescentes que integram a categoria social de "indivíduos por falta" convivem com a ideia de suspeição, ou seja, sobre eles paira a desconfiança de poderem praticar atos ilícitos. Esse entendimento leva à construção, por uma parte da sociedade, de um projeto de fracasso. Isso significa conceber um futuro perdido, onde o lugar ocupado por esses adolescentes não vai favorecer mudanças positivas da sociedade. Esses adolescentes "por falta" convivem constantemente com um paradoxo, ou seja, de serem sujeitos de direito e, ao mesmo tempo, de serem percebidos como podendo integrar um lugar desfavorecido, o que aqui denominamos projeto de fracasso. Há a produção subjetiva de um mal-estar. Propomos a hipótese (Carreteiro, 2012) de que o mal-estar é produzido na diferenciação e na discriminação social e institucional. Esse sentimento se constrói na relação, seja ela com atores institucionais, midiáticos ou em outras relações sociais. Esses adolescentes participam 
de diferentes redes sociais e muitas delas produzem vínculos sociais que podem ter olhares de suspeição. Essas percepções recaem sobre eles, tornando-se uma segunda pele, a pele social negativa.

A suspeição, a princípio, é uma categoria aberta, significa a possibilidade de terem atitudes que fogem à norma, a possibilidade de condutas ilícitas. Neste sentido, há o esboço de um reconhecimento negativo, promotor de mal-estar, nem sempre consciente. Ele, na maioria das vezes, apresenta-se como um sentimento difuso, o qual se tenta evitar.

Estes dois projetos se situam em polos bem diferenciados, mas não excluímos a existência de outros. Cada um deles atrai diferentes projetos, que podem estar situados mais próximos ou afastados do núcleo de realização ou de fracasso. É importante pensar que não haverá uma determinação na trajetória dos jovens, mas imaginários prevalentes nos diferentes locus sociais.

A adolescência, como sabemos, é uma etapa da vida socialmente construída (Gutton, 2006; Ariès 1978). Ela é atualmente concebida como um período do ciclo de vida entre o sair da infância e o ir para outro lugar sociopsíquico ainda desconhecido. É um momento de procura de si, quando o jovem visa criar novas identificações e se distanciar das anteriores (parentais e outras). O grupo de pares será muito importante, pois é integrado por sujeitos que vivem a mesma procura e o desejo de ter experimentações novas. O desejo do novo, de buscar novas sensações pauta o processo adolescente. Nessa procura, o corpo ganha um forte peso. Ele é o grande suporte das novas experiências, da sensualidade e da sexualidade. No corpo vibram o gozo, as emoções tristes e alegres. Nesta fase da vida, tendendo se destacar e ter posições consideradas próprias, o adolescente pode afirmar diversas posturas: de timidez, de sedução, de interrogação, de zoação (Carreteiro \& Ude, 2007) de hiperatividade, entre outras.

A experimentação tem um papel de destaque e conta com aspectos muito criativos e, às vezes, também perigosos. Os adolescentes podem promover desafios heroicos, no ímpeto de afirmar a diferença. Mas a forma como as ações adolescentes são recebidas pelas instituições sociais (Carreteiro, 2007), depende do lugar social ocupado pelo jovem e sua família. As experimentações podem vir a ter um caráter provisório ou permanente. Algumas experimentações podem encerrar condutas delituosas pequenas ou grandes. As ações consideradas fora da norma têm destinos diferentes. São os suportes sociais que os adolescentes dispõem que poderão 
favorecer que sejam provisórias ou se tornem permanentes. Aqueles que vivem em estratos sociais pautados pelo excesso - e aqui retornamos a Robert Castel - têm muito mais chances que as experiências perigosas ou excessivas se convertam em provisórias. No entanto, os que compõem os estratos sociais por falta têm muito mais probabilidade de terem suas ações transformadas paulatinamente em carreiras delinquentes. O que nos leva a pensar que muitos adolescentes são violentados e violentadores.

Os dados estatísticos ajudam a compreender o mal-estar sentido na pele dos adolescentes. Os homicídios são hoje a principal causa de morte de jovens de 15 a 29 anos no Brasil e atingem especialmente jovens negros do sexo masculino, moradores das periferias e áreas metropolitanas dos centros urbanos. As estatísticas mostram que mais da metade dos 65.602 mortos por homicídios, em 2017, no Brasil, eram jovens (27.471, equivalente a 52,63\%), dos quais $77 \%$ negros (pretos e pardos) e 91,8\% do sexo masculino (XII Anuário de Segurança Pública, 2018) .

A prisão dos jovens representa mais de $50 \%$ da população carcerária brasileira. Esse dado aponta para mais uma forma de vitimização da população jovem ${ }^{1}$.

Outra observação que podemos entender é que a exposição de parte do segmento jovem brasileiro a situações cotidianas de violência evidencia uma imbricação entre aspectos socioeconômicos, ideológicos e culturais, provenientes de representações negativas que lhes são imputadas. Estes dados nos ajudam a entender o projeto de fracasso. A morte dos jovens produz um destino. A morte é a ponta mais cruel do projeto de fracasso.

1. Alguns estados estão mudando estes dados. No Distrito Federal, no sistema socioeducativo a internação de adolescentes diminuiu $67 \%$ e a internação provisória $2 \%$. E a semiliberdade aumentou $2 \%$.

Além de grave violação dos direitos humanos, refletindo-se no sofrimento silencioso e insuperável de milhares de jovens, famílias e comunidades, a violência impede que parte significativa dos jovens brasileiros usufrua de um projeto de realização.

O conjunto destes argumentos nos leva a afirmar que, apesar de a adolescência ser uma categoria que é estudada por um conjunto de disciplinas (sociologia, antropologia, história, economia, psicologia), ela deve ser considerada em sua pluralidade, razão pela qual propomos em considerá-la no plural, e denominá-la adolescências. Existem na adolescência, como vimos, aspectos que são transversais a todo adolescente, mas o lugar social que cada um ocupa lhe proporcionará ancoragens sociais bastante diferenciadas, o que acarretará trajetórias igualmente diferentes. 


\section{Reconhecimento sociopsíquico}

Abordamos a construção subjetiva levando em conta o reconhecimento. Axel Honnett (2000) enfatiza a necessidade de cada indivíduo em ser reconhecido como sujeito singular, digno de amor, digno de ser considerado como um verdadeiro cidadão, reconhecido pelos outros e reconhecendo os outros. Tal afirmação permite traçar uma ponte com o conceito de "contrato narcísico", formulado pela psicanalista Piera Aulagnier (1978). O contrato ajuda a pensar as lógicas e os investimentos estabelecidos entre o sujeito e o conjunto social. Para Aulagnier, o investimento narcísico só é possível se a trama social da qual os sujeitos participam puder lhes investir narcisicamente. Este processo confere ao sujeito um lugar de portador de continuidade no conjunto social. O reconhecimento social, em sua vertente positiva, é então portador de narcisismo.

O contrato narcísico conduz o sujeito a ter o desejo de assumir a continuidade do conjunto sociofamiliar do qual participa. Podemos imaginar que a escassez do investimento social ou o investimento na esfera negativa possa levar a fragilizar os vínculos sociais juvenis e a produzir um déficit narcísico psicossocial, que conduz ao mal- estar e ao sentimento de desamparo.

De forma geral, as instituições deveriam poder participar do reconhecimento dos sujeitos adolescentes pela via da positividade e da promoção de sentimentos de pertencimento. Existem locus privilegiados de construção dos afetos adolescentes, como o grupo de pares, a família e a escola. Não devemos desprezar também os outros contextos institucionais, visto que o reconhecimento do sujeito deve estar presente em todas estas dimensões.

O sistema socioeducativo tem mais possibilidade de capturar os adolescentes que aqui denominamos por falta do que os demais. No entanto, sabemos da preocupação de muitos profissionais deste sistema em poder refletir sobre suas práticas e de colocá-las em análise (Pereira de Andrade \& Amaral Machado, 2017). Na nossa perspectiva, para se abordar esta problemática convém levar em conta diversas dimensões, o que nos faz citar a sua complexidade.

\section{Complexidade das comunidades de afetos e as intervenções socioclínicas}

A área da comunicação (Paiva, 2012) discute muito a terminologia "comunidade de afeto". Ela é concebida como possibilidade de vinculação em que o afeto, a simpatia, a igualdade de interesses e de partilha definem os contatos. Enfatiza-se o contexto 
atual que se caracteriza por grande densificação tecnológica e por altíssimo fluxo de informação a partir de novos mecanismos de conexão, modos de estar juntos.

Pode-se pensar - como veremos - as comunidades de afeto, na perspectiva adolescente, enfocando os diversos vínculos construídos junto às instituições e aos profissionais institucionais, aos grupos de pares e à família.

Na nossa perspectiva, o afeto pode ser considerado em várias acepções. Há os sentimentos que se inscrevem em uma perspectiva positiva, estes envolvem a criação, o aprimoramento e a continuidade de vínculos. Existe um interesse pelo outro, considerado em sua alteridade. Há também uma acepção diferente, os sentimentos que atacam os vínculos e que buscam destruí-los. No entanto, quaisquer que sejam os afetos, as relações e os vínculos sociais serão sempre atingidos, de modo positivo ou não.

Para a psicanálise, os afetos são os modos de representações das pulsões de vida e de morte (Laplanche \& Pontalis, 2000). Eles incluem um espectro bastante amplo de sentimentos. Eugène Enriquez (1994) considera existir um dinamismo pulsional que sempre se articula com muitas outras dimensões institucionais, sociais, grupais, familiares, históricas, ideológicas e políticas.

Consideramos que enfatizar a comunidade de afeto juvenil requer pensar na rede social e institucional da qual os adolescentes participam.

Aqui pensamos nas medidas socioeducativas. Elas se apoiam nas diretrizes dos direitos humanos e se voltam para a implementação de políticas públicas previstas no ECA e estabelecem

regras e critérios de caráter jurídico, político, pedagógico, financeiro e administrativo que devem ser seguidos durante o processo de apuração de ato infracional cometido por adolescentes até a execução de medidas socioeducativas. Além disso, propõe as medidas em meio aberto (prestação de serviço à comunidade e liberdade assistida) em preferência às restritivas de liberdade, as quais somente devem ser aplicadas em caráter excepcional, nos casos de atos infracionais mais graves. $O$ documento orienta, ainda, para a articulação das políticas intersetoriais em nível local e a constituição de redes de apoio nas comunidades (Costa, Penso, Sudbrack \& Jacobina, 2011).

Para adentrarmos a questão do afeto na perspectiva socioclínica, cabe perguntar quais posturas clínicas podem estar presentes junto aos profissionais que trabaIham com os adolescentes nos vários tipos de medidas. Discutiremos três delas: 
i. a clínica e a abordagem clínica;

ii. a implicação; e

iii. a escuta.

A clínica e a abordagem clínica...

A clínica não é unicamente restrita à psicoterapia ou à psicanálise, apesar de ter se desenvolvido muito nestes campos. Outros profissionais podem ser sensíveis a ela. A clínica referida aqui é aquela que engloba o social e o institucional, ou seja, a clínica enquanto abordagem.

Toda clínica inclui uma relação na qual há certa tensão, alguma forma de sofrimento e também de prazer, há o desejo de se atribuir sentidos ao sofrimento, ou a situação com a qual estamos sendo confrontados. A situação é um conceito importante. Ela pode ser considerada, ao mesmo tempo, em sua singularidade e em sua transversalidade. Por ser singular é única, mas, ao mesmo tempo, tem semelhanças com outras, daí seu aspecto transversal. Ela também é ocupada por um espaço e um tempo, por limitações e por indícios de potência. No caso dos adolescentes, deve-se estar atento às suas histórias pessoais e àquela que se tece fora e dentro da instituição onde ele está.

A clínica implica também uma postura de questionamento. Ela nos leva a interrogar em permanência os modos de construção, as funções, as significações, os aspectos defensivos e inovadores que a situação tem naquele momento. Deste modo, não se pode negligenciar o lugar institucional onde está o profissional. A instituição tem projetos e exigências e uma cultura organizacional.

A clínica nos remete ainda a uma ética. Como podemos estar com o outro e considerá-lo como sujeito - ou seja, não assujeitá-lo - e, ao mesmo tempo, responder às exigências da situação? O outro nem sempre é um sujeito individual, ele pode ser coletivo. No entanto a mesma postura ética e de interrogação faz-se necessária.

A atitude clínica não deve perder de vista a análise dos sentidos das ações dos diversos protagonistas, das dinâmicas que são permanentemente criadas, da avaliação das forças autônomas ou heterônomas (Castoriadis, 1982) que compõem o campo de trabalho. A clínica social deve poder agregar os diversos atores sociais e institucionais. 


\section{A implicação}

A implicação, seguindo Enriquez (2001), não se concebe sem simpatia e distância. Tal premissa traz implícita uma grande dificuldade, qual seja, conseguir o equilíbrio entre essas duas dimensões. A simpatia significa o interesse pelos sujeitos (individuais ou coletivos) com os quais estamos trabalhando, eles nunca são estranhos ao sociólogo clínico (Barus-Michel, 2004). A implicação é igualmente o engajamento, a responsabilidade, a subjetividade e a intersubjetividade (Amado, 2013). A implicação participa sobremaneira do tipo de escuta que se tem da situação. Ela se torna um instrumento privilegiado da análise da situação. É preciso entender a implicação como a capacidade de se abrir ao sentido, de acolhê-lo e em primeiro lugar admiti-lo onde ele nos atravessa. Essa é a melhor oportunidade para apreendê-lo. Isso não quer dizer imergir nele, mas reconhecê-lo, o que supõe ao mesmo tempo uma distância (Barus-Michel, 2004: 126).

Devemos fazer uma distinção entre simpatia e identificação. A simpatia permite nos acercarmos das pessoas, enquanto a identificação não cria a distância necessária. No entanto, a análise da implicação permitirá entender quais sentimentos atravessam o profissional. Muitas vezes a própria identificação os invade. Neste momento pode se admitir a existência dos diversos sentimentos, buscar acolhê-los e decifrar as possíveis significações que apresentam. Ao ser afetado pelos sentimentos, pode-se buscar adentrar na compreensão da situação. Tal atitude reflexiva favorece encontrar modos de sair ou transformar a posição dos profissionais na situação, criando a distância necessária para compreendê-la e atuar.

Pensar na implicação é poder colocar em análise a história pessoal e social, as questões políticas que atravessam os trabalhos. E também poder trabalhar com os estereótipos que têm os profissionais. São os adolescentes sujeitos ou infratores? Não se pode desconsiderar o ato infracional, mas não se pode fazer com que este assuma a identidade mesma do sujeito.

A implicação refere-se também a vivenciar os dilemas que, muitas vezes, estão presentes nas prescrições relativas às atividades esperadas dos técnicos, como, por exemplo, a elaboração de relatórios psicossociais. A questão que se coloca - como mostram Liana F. Costa, Maria Aparecida Penso, Maria Fátima Sudbrack; Olga Maria Jacobina (2011) - é como realizá-los levando em conta a história de vida sociofamiliar do adolescente e, ao mesmo tempo, poder oferecer subsídios à demanda da Justiça. Muitas vezes o profissional que trabalha no sistema socioeducativo vive o impasse de ser um profissional do entre, de estar de um lado com o adolescente e a família e de ter de atender outras demandas judiciais em relação ao mesmo adolescente. 
Uma das demandas é a produção de relatório sobre o jovem. Essas questões não podem fugir às formas de vivenciar a implicação.

É justamente mediante a análise da implicação que se contribui para que a situação avance, tome outros contornos. Jacqueline Barus-Michel (2004) diz que somos nosso primeiro objeto de análise, e que isso permite encontrar uma distância necessária para se refletir sobre o que fazer e como fazer.

\section{A escuta enquanto postura}

A ética da escuta do sofrimento parte da ideia motora do reconhecimento do sofrimento do outro e do nosso próprio. A perspectiva clínica vai supor uma sensibilidade particular vis-à-vis o outro.

A escuta só é efetiva se aquele que escuta estiver implicado em um duplo movimento que se opera de forma articulada. Escutar o outro é também poder escutar a si mesmo. Escutar é estar continuamente atento à implicação e ao conjunto dos atravessamentos que afetam o processo de estar com o outro; é neste sentido que a escuta leva em conta o contexto situacional no qual ela ocorre.

Escutar é poder permitir os desdobramentos da pulsão epistemofílica (Freud, 1996 [1905] apud Enriquez, 1993b), que faz sua emergência em um horizonte de interrogação, de dúvida e de desejo de compreender. Escutar é ainda estar ciente de que a pulsão de domínio (Enriquez, 1993b), de desejo de controlar, buscará ser sempre atuante. Em síntese, é atentar para a dualidade do trabalho pulsional e poder pensar, interrogar como o campo da atividade pode fortalecer mais uma ou outra vertente da dimensão pulsional. Escutar é poder desenvolver uma escuta plural: estar sensível aos vários atravessamentos que têm as situações.

Escutar em situações de trabalho é ainda estar atento às defesas coletivas que podem ser ativas para a manutenção da organização de trabalho, como enfatizam os estudos da psicossociologia (Lhuilier, 2006) e da psicodinâmica do trabalho (Dejours, 1989). O sofrimento, segundo essa abordagem, é fruto da organização do trabalho. Para poder ser escutado, ele não deve ser abstraído das condições organizacionais que o engendraram, o sustentam, bem como das defesas coletivas que existem em torno dele.

Manter uma postura clínica - levando em consideração a escuta, a implicação e a análise da situação - permite construir dispositivos de trabalho junto aos adolescentes. A princípio não existe um único dispositivo, estes são construídos de acordo 
com as situações, os diversos atores envolvidos e as possibilidades e limites institucionais. Neste sentido, a ênfase à singularidade é bastante pertinente.

A sociologia clínica e a psicossociologia consideram ser importante atentar para estas posturas nos trabalhos realizados. Os afetos considerados em uma dimensão da complexidade perpassam todas as relações.

Não se pode ser ingênuo a ponto de esperar que os adolescentes aceitem a priori os trabalhos socioeducativos. Os jovens estão enquadrados institucionalmente por terem cometido alguma ação considerada como sujeita a ser julgada pela Justiça. Foi a inscrição da Lei que os remeteu a instituição onde há certa tutela. Deste modo, a relação com os profissionais é marcada por todos estes limites. Eles estão presentes no vínculo formado com os profissionais e a instituição. As relações estabelecidas, apesar de serem bastante diferenciadas, podem ser pautadas por silêncios, pela obrigação, pela violência, pelo não engajamento ou também por fortes identificações dos adolescentes. A perspectiva clínica, ao dar ênfase à implicação, remete à importância da atenção aos sentimentos dos profissionais e aos vínculos que se tecem, sempre tendo em vista que a presença do jovem se enquadra em um projeto institucional.

\section{Tipos de comunidades de afeto no horizonte juvenil}

Podemos pensar na comunidade de afeto junto ao grupo de pares, à família, à escola, à saúde, a contextos profissionais, de lazer, entre outros. Em síntese, aos grupos que constituem a rede social juvenil. Mais uma vez, o afeto é observado de forma complexa, como pudemos justificar anteriormente. Convém interrogar que vínculos são estabelecidos nestes diversos contextos, quais as dinâmicas prevalentes.

Na família, indagar sobre as relações sociais, quais são mais predominantes, qual o nível socioeconômico, como se constroem as relações familiares, quem exerce autoridade, como circula a função da Lei. Compreender a dinâmica familiar presente e a história familiar articulando-a continuamente com as relações sociais pode ser de grande importância para fornecer elementos para o entendimento da posição ocupada pelo adolescente na família.

No grupo de pares, quais elementos permitem formas de identificação positivas ou não entre os adolescentes e os outros sujeitos; quais personagens são idealizados, quais os temidos ou considerados como tendo posturas heroicas. Como ocorrem as 
relações de gênero? Quais atividades são desenvolvidas? Onde ocorrem os encontros dos grupos e como eles circulam no espaço da cidade, como se dá o ir e vir?

Na escola podemos empregar o mesmo questionamento sobre a importância dos grupos, mas, ao mesmo tempo, pensar no sentido da função da aprendizagem e na relação estabelecida com os professores.

Envolver a família, os grupos e demais instituições junto aos adolescentes representa uma forma de atuar em uma perspectiva de rede. Essa é fundamental para o andamento do trabalho e os vínculos juvenis, atentando para as dificuldades, as potencialidades e os desafios que existem nos diversos contextos.

A atitude do profissional pode ser propulsora de reflexões. A escuta do conjunto das situações terá um duplo objetivo: compreendê-las com o propósito de cumprir um projeto institucional, o qual solicita uma avaliação do jovem e permite intervir a partir dessas compreensões, com o objetivo de propiciar ações reflexivas junto aos sujeitos, às famílias e aos grupos envolvidos. É neste sentido que podemos dizer que são criados modos qualitativos de intervenções.

Para poder contribuir de modo positivo na construção subjetiva do adolescente e favorecer a elaboração de um projeto, o profissional deve ter como norte que a filiação de todo sujeito é psico-sócio-política. Desde o nascimento, qualquer indivíduo participa de uma dupla filiação: por um lado há a familiar, por outro, a cidadã.

\section{Filiação familiar}

Ser filho é se inscrever na linha de continuidade da espécie humana e da família. Todo filho é herdeiro, recebe os valores e os ideais dos progenitores ou daqueles que exercem esses papéis. As transmissões parentais podem ser convergentes, divergentes ou mesmo ambivalentes.

Ser filho é também herdar os conflitos entre gerações, conscientemente ou não. É herdar os projetos que os pais (ou outras referências parentais) construíram para ele.

\section{Filiação cidadã}

Na linhagem social, ser cidadão é passar a ocupar um lugar na sociedade. É se inscrever em um registro de direito e de deveres sociais. Esta filiação também traz diversas heranças sociais. Fora a dimensão legal, há outra, o lugar que as instituições 
dispensam aos diferentes cidadãos. A legitimidade que as instituições Ihes proporcionam no gozo dos direitos e na relação com os deveres. Esta dimensão também está incluída na herança familiar. Os pais também são herdeiros de aspectos sociais e as transmissões que fazem aos filhos são atravessadas por estes aspectos. Ao nos referirmos à filiação social, consideramos o eixo da herança sociofamiliar e o lugar atribuído pelas diversas instituições aos diferentes cidadãos.

Muitos sentem o peso da filiação social negativamente e se sentem como cidadãos diminuídos, minimamente assistidos pelo sistema social, às vezes mesmo colocados à parte, rejeitados, sendo objeto de desconfiança e, às vezes, de ódio.

A filiação familiar e cidadã funcionam sempre de forma bastante articulada. Toda família, apesar de sua singularidade, será sempre atravessada pelo social. A construção subjetiva de qualquer sujeito é intimamente vinculada a ambos os eixos. Deste modo, os projetos institucionais elaborados em uma perspectiva singular devem levar em consideração estas filiações.

\section{O reconhecimento no trabalho socioeducativo e o lugar da rede}

Se até aqui nos referimos ao trabalho junto ao jovem é também necessário voltarmos a atenção ao trabalhador que atua no sistema socioeducativo.

Frisamos a importância do reconhecimento para a construção subjetiva do adolescente, mas é importante também pensar no reconhecimento do sujeito trabalhador e por onde passa este reconhecimento nas atividades de trabalho.

Buscar meios de fortalecer os coletivos de trabalho, poder dividir com ele realizações, angústias e limitações é um modo de trabalhar de forma não individualista e de procurar novas criações. Convém precisar que a formulação do trabalho socioeducativo traz em sua concepção uma grande inter-relação dos coletivos. Nos dias atuais, onde o individualismo e a competição são muito grandes, vale apostar na construção de coletivos e em modos de resistir e de buscar prazer no trabalho, sem, contudo, esquecer o sofrimento.

O trabalho neste sistema tem na rede institucional uma vertente muito forte, visto que o adolescente é encaminhado a integrar várias instituições. O reconhecimento do trabalho de outros profissionais nos múltiplos pontos da rede é mister. A atividade profissional não pode ser unicamente a de fazer encaminhamentos burocráticos, mas de poder realmente acompanhar os jovens, de discutir com os colegas 
sobre o trabalho realizado, os entraves, as formas de desobstrução e de facilitação. Enfim, pensar no jovem como sujeito de direito e na forma como as instituições estão participando em sua produção subjetiva e cidadã.

\section{À guisa de conclusão}

Neste artigo, orientado pela sociologia clínica e pela psicossociologia, quisemos discutir de forma sucinta os lugares que são atribuídos aos adolescentes na sociedade. Isto nos encaminhou a pensar em um dos destinos institucionais do jovem, que participa da categoria de indivíduos por falta, o sistema socioeducativo. Almejamos apontar a importância de se pensar na clínica social para os profissionais que trabalham neste campo institucional. Sabemos do grande desafio que é realizar trabaIhos socioeducativos, pois o seu usuário carrega um peso de grande estigmatização.

Os adolescentes que integram o sistema socioeducativo participam pouco das instituições. A escola e a Justiça são as mais presentes em suas vidas. No entanto elas são bastante diferenciadas. A primeira remete a identidade de aluno, enquanto a segunda marca o caráter de delito. A questão que se coloca é como, na prática institucional, pode se manter fiel ao ECA e enfatizar o que ele apregoa - ser o adolescente sujeito de direito.

Buscamos levantar essas questões sem, no entanto, ter uma visão romântica, mas realista, enfatizando as angústias, os sofrimentos e os conflitos. Na perspectiva clínica, estes últimos são reveladores das contradições e tensões (Gaulejac, 2019). O conflito então não é algo a ser eliminado, mas incluído no campo de trabalho e é deste modo que a clínica social acompanha o conjunto das atividades dos profissionais. Ela não os deixa refratários aos sofrimentos, mas propõe que eles sejam analisadores das situações. O profissional, ao assumir o seu lugar de sujeito, vai permitir ao outro também poder ter essa posição.

Finalizamos com uma citação de Cornelius Castoriadis no final de um dos capítulos do livro Le monde morcelé (1997). O autor refere-se a um diálogo hipotético. Uma pessoa pergunta para outra: O que você quer então? Mudar a humanidade? E a outra responde: "Não, eu quero uma coisa infinitamente menor: que a humanidade mude". 


\section{Referências}

XII ANUÁRIO BRASILEIRO DE SEGURANÇA PÚBLICA, 2018. Disponível em: $<$ http://www.forumseguranca.org.br/publicacoes/anuario-brasileiro-de-seguranca-publica-2018/>. Acesso em: 20 Ago. 2019.

AMADO, G. Implicação. In: BARUS-MICHEL, J.; ENRIQUEZ, E.; LEVY, A. (Orgs.). Dicionário de psicossociologia, p. 367-374. Portugal: Editora Climepsi. 2013.

ARIÈS, P. História social da criança e da família. Rio de Janeiro: Zahar, 1978

AULAGNIER, P. La violence de l'interprétation. Paris: Presses Universitaires de France, 1978.

BARUS-MICHEL, J. Souffrance. Sens et croyance, Paris: Éditions Érès, 2004.

CARRETEIRO, T. C. O. C. Adolescências nas malhas do tráfico. In: AMPARO, D.; ALMEIDA, S.; BRASIL, K.; GANDOLFO, M.; MARTY, F. (Orgs.). Adolescência e violência: intervenções clínicas, psicossociais e educativas, p. 110-119. Brasília: Editora UnB, 2012.

- Famílias confrontadas com o trabalho futuro dos filhos - um projeto de pesquisa. In: FERES- CARNEIRO, T. (Org.). Familia e casal: saúde, trabalho e modos de vinculação, p. 181-201. São Paulo: Casa do Psicólogo, 2007.

CARRETEIRO, T. C. O. C.; UDE, W. Juventude e virilidade: a construção social do etos guerreiro. Revista Pulsional de Psicanálise, v. 191, p. 63-73. São Paulo: Escuta, 2007.

CASTEL, R. Les métamorphoses de la question sociale. Paris: Fayard, 1995.

CASTORIADIS, C. Le monde morcelé. Paris: Les Éditions du Seuil, 1997.

— . Instituição imaginária da sociedade. 5. ed. Rio de Janeiro: Paz e Terra, 1982.

COSTA, L. F; PENSO, M. A.; SUDBRACK, M. F. O.; JACOBINA, O. M. P. Adolescente em conflito com a lei: o relatório psicossocial como ferramenta para promoção do desenvolvimento. Psicologia em Estudo, v. 16 n. 3, Maringá, Jul./Set. 2011

DEJOURS, C. A loucura no trabalho. São Paulo: Cortez, 1989.

DURKHEIM, E. Les règles de la méthode sociologique. Paris: Presses Universitaires de France, 2013 [1895]. 
— . As regras do método sociológico. São Paulo: Martins fontes, 2007.

ENRIQUEZ, E. Instituições, poder e "desconhecimento" In: ARAÚJO, J. N. G.; CARRETEIRO, T. C. (Orgs.). Cenários sociais e abordagem clínica, p. 49-74. São Paulo; Belo Horizonte: Escuta; Fumec, 2001.

. A organização em análise. Petrópolis (RJ): Vozes,1994.

- L'approche clinique: genèse et développement en France et en Europe de I'Ouest. In. DE GOULEJAC, V. ; ROY S. (org). Sociologies cliniques, p. 19-35. Marseille: Hommes et perspectives, 1993a.

. L'analyse clinique dans les sciences humaines. In: ENRIQUEZ, E.; HOULE, G; RHEAUME, J; SEVIGNY, R. (Orgs.). L'analyse clinique dans les sciences humaines, p. 181-195. Montreal: Éditions Saint-Martin, 1993b.

GAULEJAC, V. de. Épistémologie de l' intervention socioclinique. In: VENDEVELDE-ROUGALE, A. ; FURGIER P. Dictionnaire de sociologie clinique, p. 252-256. Paris: Éditions Érès, 2019.

. La societé malade de la gestion: idéologie gestionnaire, pouvoir managériel et harcelement social. Paris: Les Éditions du Seuil, 2005.

GAUlEJAC, V. ; TABOAdA, I. La Lutte des places. Paris: Hommes et Perspectives, 1994.

GUTTON, P. Parentalité. Revue Adolescence, v. 24, n. 1, p. 9-32, 2006.

HONNETH, A. La lutte pour la reconnaissance. Paris: Éditions du Cerf, 2000.

LAPLANCHE, J.; PONTALIS, J.B. L. Vocabulário da psicanálise. São Paulo: Martins Fontes, 2000.

LHUILIER, D. Cliniques du travail. Paris: Éditions Érès, 2006.

PAIVA, R. A comunidade do afeto. Revista Matrizes, v. 6, p. 63-75, São Paulo, ECA/ USP, 2012.

PEREIRA DE ANDRADE, A.; AMARAL MACHADO, B. Justiça juvenil: paradigmas e experiências comparadas. Brasília: Fundação Escola Superior Marcial Pons, 2017.

YZAGUIRRE, F.; CASTILLO MENDOZA, C. A. La perspectiva de la sociología clínica: una sociología de proximidad orientada al sujeto. In: "Crisis y cambio: propuestas desde la sociología”. Actas Del XI Congreso Español de Sociología, p. 832-840, 2013. 